\title{
Identifying and prioritizing the factors of service experience in banks: A Best- Worst method
}

\author{
Shahrbanoo Yadollahi ${ }^{a}$, Ali Kazemi ${ }^{b^{*}}$ and Bahram Ranjbarianc
}

\begin{tabular}{l}
${ }^{a} \mathrm{PhD}$ candidate of Business Management, Department of Management, University of Isfahan, Isfahan, Iran \\
${ }^{b}$ Assistant Professor of Management, Department of Management, University of Isfahan, Isfahan, Iran \\
cProfessor of Management, Department of Management, University of Isfahan, Isfahan, Iran \\
\hline C H R O N I C L E
\end{tabular}

Article history:

Received November 12, 2017

Received in revised format:

December 20, 2017

Accepted January 4, 2018

Available online

January 5, 2018

Keywords:

Service experience

Banking service

Service marketing

Best-Worst Method

Multi-criteria decision making

\begin{abstract}
The present study aimed at identifying and evaluating the factors affecting the service experience at the touch points of banking services. These factors were prioritized to help the managers understand the most important factors for achieving the favorable service experience. In this study, the theoretical foundations and interviews with customers were used to identify the factors forming the service experience at touch points. Then, the Best-Worst method (BMW) was used to evaluate and determine the significance of each identified factor. Sixteen customers participated in the interview and ten customers participated in the study by the BMW method. Six touch points and 34 factors forming the service experience were created at these points of interview analysis. The research findings showed that 'service process' and 'interaction customer-employees' for creating a favorable experience are significant in banking services. In addition, the findings showed that bank managers should allocate their resources for improving them to achieve the competitive advantage.
\end{abstract}

C 2018 by the authors; licensee Growing Science, Canada.

\section{Introduction}

Recently, the power of customers to determine the conditions of transaction has increased. Therefore, the organizations cannot satisfy the customer expectations merely by delivering their services anymore because the customers are willing something beyond that. In addition to receiving service, customers tend to achieve a favorable experience (Bateson, 1995). Most service providers, especially banks, have the similar products and services. Since in these types of services, customers have less tendency towards switching from their existing bank due to the costs and they have to continue receiving the bank services (Licata \& Chakraborty, 2009). However, their negative word of mouth leads to attracting fewer customers (Rajaobelina \& Bergeron, 2009). Thus, service providers need to seek the ways to differentiate themselves from their competitors in the market. In order to achieve this goal, service providers constantly require to acquire new customers and to retain them by delivering services beyond the customer expectations. Using the service experience approach is one of the methods to achieve this * Corresponding author.

E-mail address: alik@ase.ui.ac.ir (A. Kazemi)

C 2018 by the authors; licensee Growing Science, Canada. doi: $10.5267 /$ j.dsl.2018.1.002 
goal (Pine \& Gilmore, 1998; Verhoef et al., 2009). The concept of service experience was first introduced by Holbrook and Hirschmann in 1982 in marketing literature. They emphasized the consumption embraces experiential aspects and hedonic experience. They argued that the customers' consumption behaviors are not only a rational decision making based on information, but also a consequent emotional contents of the personal interaction (Holbrook \& Hirschman, 1982). Research on superior and memorable service experiences has recently gained greater attention (Pine \& Gilmore, 1998; Shaw \& Ivens, 2003). Service experience has been defined by Meyer and Schwager (2007) as "an internal and subjective response that customers have to any direct or indirect contact with a company" (p.118).

The subjective nature of experience indicates that the experience is inherently personal because it is shaped in the mind of each customer based on his interaction with cognitive, sensorial, emotional, rational, physical, and spiritual levels (Pine \& Gilmore, 1998). Furthermore, service experience is an internal psychological state and therefore experience can be considered as a multi-dimensional and individual to each customer (Gentle et al., 2007). On the other hand, customers require to engage in a journey for receiving services. During this journey, the overall service experience is created from the customer exposure to the different phases such as search, evaluation, purchase, consumption, and postpurchase activities (Verhoef et al., 2009). This experience is formed not only through the customer exposure to controllable factors (e.g. advertisement, price, and servicescape), but also through the exposure to uncontrollable ones (e.g. the influence of others customer) (Verhoef et al., 2009). From this perspective, each moment of planned or unplanned encounters, direct or indirect customer interaction with any part of the organization was recognized as touch point (Meyer \& Schwager, 2007; Rosen \& Waller, 2009). At each touch point, customers form their judgments consciously or unconsciously evaluate their experiences. Thus, identifying the factors forming the service experience at touch points can be interpreted only from the customer's point of view (Lemke et al., 2011).

In recent years, a lot of attention was paid to identify and measure the service experience construct helping the managers create a favorable service experience (Gentile et al., 2007; Meyer \& Schwager, 2007; Verhoef et al., 2009). Previous studies have focused on the factors of service experience in banking services. Garg et al. $(2012,2014)$, for instance identified the success criteria and sub-criteria of bank service experience including the affective (customization, core service, online hedonic elements and value addition), sensorial (servicescape and online aesthetics), cognitive (convenience, marketing mix and online functional elements), behavioral (employees, speed, service process), and rational (customer interaction and presence of other customers) aspects. The cognitive factor was the most significant among all the main criteria and convenience factor is the most important among all the sub-criteria in service experience success (Garg et al., 2012, 2014). Grace and O'cass (2004) also indicated that the core service, employee service, and servicescape make a very significant contribution to the service experience respectively (Grace \& O'Cass, 2004). Rahman (2006) reported the servicescape, usability and availability technology, speed process, and employees as the factors affecting the service experience (Rahman, 2006). Chahal and Dutta (2015) showed the factors of core experience (cognitive, affective and behavioral), rational experience, and sensory experience as the factors in creating service experience. Among them cognitive experience (e.g. knowledge and competency of employees) has been recognized as the most important component (Chahal \& Dutta, 2015). All the above-mentioned studies referred only to some factors of service experience at touch points from the viewpoints of the bank managers and employees. Since the service experience is subjective and individual, it is necessary to be evaluated from the customer's point of view. Although most studies considered the measurement of service experience at some touch point, service experience originates from the interaction of customer with an entire set of touch points during customer journey. Each touch point has a distinctive significance precisely from the customers' viewpoint which needs to be considered by the managers. Due to the limitation of resources and time, the service providers identify the key factors and then they prioritize the most important ones to allocate their resources in 
order to enrich the service experience and increase customer satisfaction. Thus, the present study aimes at identifying the factors forming the service experience at touch points and prioritizes them according to customers' viewpoints. To the knowledge of the authors, a limited number of studies have been addressed this issue in Iran. The present study thus, uses some interview with customers to identify the factors forming the service experience. The obtained results are presented in the next section.

\section{Material and methods}

In this study, the mixed-mode research method was used for data collection. Two steps were considered for data collection. At the first step, the factors and sub-factors of bank service experience were identified through literature studies and semi-structured interviews with customers. Then, the relative significance of the factors and sub-factors was identified by the BMW method and by distributing the questionnaires among the bank customers. Excel software was used to calculate the weight and consistency rate.

\subsection{First step: quantitative method}

At the first step of the data collection, 16 customers with different demographic features (age, gender, education) were used. The interviews were recorded by a digital recorder and then transcribed and analyzed. The average time for the interviews was 30 minutes. The interviews were conducted based on the purposive sampling method of theoretical sampling type from the bank customers. The researchers were referred to the bank branches to access the customers and selected some of them randomly for the interview. The interview data collection was sufficient to ensure saturation. Then, the data were encoded and analyzed by using the thematic analysis and the themes were made. Fig. 1 is an example of forming a theme extracted from some interviews.

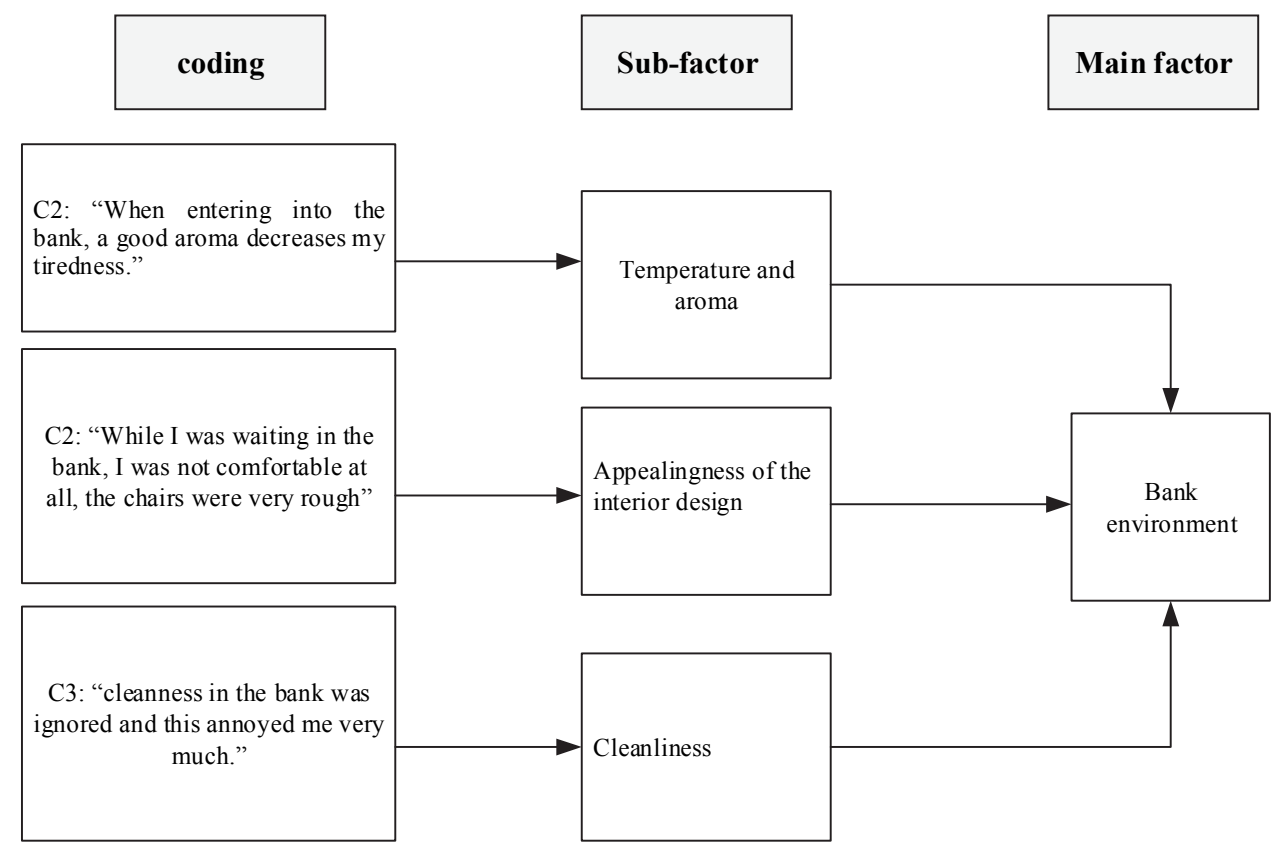

Fig 1. Theme extracted from some interviews

In addition, the necessary steps (e.g. the continuous review by two encoders and receiving feedback from experts) were conducted for confirming the reliability and validity in the obtained results. Finally, the factors and sub-factors identified from the interviews are shown in Table 1. 


\section{Table 1}

Factors of service experience

\begin{tabular}{|c|c|}
\hline factors & Sub-factor \\
\hline Interaction customer-employee & $\begin{array}{ll}- & \text { Employee's behavior } \\
\text { - } & \text { Employee's responsiveness } \\
\text { - } & \text { Employee's Knowledge and skill } \\
\text { - } & \text { Employees' appearance }\end{array}$ \\
\hline Interaction customer-customer & $\begin{array}{l}\text { - } \text { Conversation with other customers } \\
\text { - } \quad \text { Word of mouth } \\
\text { - } \\
\text { - } \\
\text { - } \\
\text { - }\end{array}$ \\
\hline Service environment & $\begin{array}{ll}\text { - } & \text { Appealingness of the interior design } \\
\text { - } & \text { Temperature and aroma } \\
\text { - } & \text { Internal Straighten } \\
\text { - } & \text { Cleanliness } \\
\text { - } & \text { Design physical product (forms, fishes,...) } \\
\text { - } & \text { Appealingness of physical product (forms, fishes, ...) } \\
\text { - } & \text { Bank branch availability } \\
\text { - } & \text { Bank architecture and design } \\
\text { - } & \text { Available parking facilities }\end{array}$ \\
\hline Service process & $\begin{array}{ll}\text { - } & \text { Waiting time } \\
\text { - } & \text { Working hours } \\
\text { - } & \text { Process speed } \\
\text { - } & \text { Process Standardization } \\
\text { - } & \text { process innovation } \\
\text { - } & \text { Process customization }\end{array}$ \\
\hline Technological & $\begin{array}{ll}\text { - } & \text { Bank technology usability } \\
\text { - } & \text { Bank technology availability } \\
\text { - } & \text { Emerging systems }\end{array}$ \\
\hline communicative & $\begin{array}{ll}\text { - } & \text { Promotional advertising } \\
\text { - } & \text { Informative advertising } \\
\text { - } & \text { Attractiveness Advertising } \\
\text { - } & \text { Informative message } \\
\text { - } & \text { Attractiveness message } \\
\end{array}$ \\
\hline
\end{tabular}

\subsection{Second step: Quantitative method}

In the second step of the data collection, the BMW method that was raised by Rezaei in 2015 was used. BWM is multi-criteria decision making method which uses an optimization model to determine the weights of the criteria. BMW method, in comparison to Analytical Hierarchy Process (AHP) method, has less pairwise comparisons and leads to more reliable solutions (Rezaei, 2015, 2016), so that in BMW method, the best criterion and the worst criterion are selected, after which the best criteria is compared to other criteria then other criteria are compared to the worst criteria. Ghaffari et al. (2017) indicated that Best-Worst method which is considered as one of the most prominent and effective MCDM methods can be used in order to evaluate the key success factors in technological innovation development of remotely-piloted helicopters (RPH) industry. Also, Askarifar et al. (2018) used BWM method to evaluate investment opportunities in Iran's seashores and also the necessary public infrastructure requirements were ranked with TOPSIS. Abadi et al. (2018) developed a strategic planning framework for development of medical tourism industry by using SWOT matrix and formulated strategies were ranked using BWM technique. This method was used for prioritizing and weighting the factors which form the service experience at the first step. The steps of this method are explained below.

Step 1- A set of decision criteria are identified.

Step 2- As per the personal preference the decision-maker selects the best criterion (e.g. the most important one) and the worst criterion (e.g. the least important one) among the available set of criteria identified in Step 1. 
Step 3- The decision-maker then carries out pairwise comparisons between the best criterion and other criteria. This is done by determining preferences using a number between 1 and 9 , where 1 is 'equally important' and 9 is 'extremely more important'. The resulting vector of this is as mentioned below:

$$
A_{B}=\left(a_{B 1}, a_{B 2}, \ldots, a_{B n}\right)
$$

Step 4 - The decision-maker then carries out pairwise comparisons between the other criteria and the worst criterion. This is done by determining preferences using a number between 1 and 9 , where 1 is 'equally important' and 9 is 'extremely more important'. The resulting vector of this is as mentioned below:

$$
A_{W}=\left(a_{1 w}, a_{2 w}, \ldots, a_{n w}\right)
$$

Step 5- In order to find the optimal weights of the criteria $\left(W_{1}^{*}, W_{2}^{*}, \ldots, W_{n}^{*}\right)$ and $\xi^{*}$.The maximum absolute differences $\left|W_{B}-a_{B j} W_{j}\right|$ and $\left|W_{j}-a_{j W} W_{W}\right|$ are reduced to minimize to obtain unique solution of weights.

$$
\begin{aligned}
& \operatorname{minmaxj}\left\{\left|W_{B}-a_{B j} W_{j}\right|,\left|W_{j}-a_{j W} W_{W}\right|\right\} \\
& \text { subject to } \sum_{j} W_{j}=1, \quad \mathrm{~W}_{\mathrm{j}} \geq 0, \text { for all } j
\end{aligned}
$$

This problem is transferred to the following linear programming problem:

$$
\begin{aligned}
& \min \xi^{*} \\
& \text { subject to } \\
& \left|W_{B}-a_{B j} W_{j}\right| \leq \xi^{*} \\
& \left|W_{j}-a_{j W} W_{W}\right| \leq \xi^{*} \\
& \sum_{j} W_{j=1}=1 . \\
& w_{j} \geq 0, \text { for all } j
\end{aligned}
$$

Solving the problem presents the optimal weights $\left(W_{1}^{*}, W_{2}^{*}, \ldots, W_{n}^{*}\right)$ and $\xi^{*}$. More over, $\xi^{*}$ can be considered as an indicator of consistency of comparisons. There is a high level of consistency for values close to zero (Rezaei et al., 2018; Rezaei, 2016). For this study, there is a set of factors each of which has some sub-factors. Weighting is done for the six main factors (service process, interaction customeremployee, technological factor, bank environment, communicative factor, interaction customercustomer) and also for the sub-factor, which provides local weights. For obtaining the global weights for each sub-factor the weights of the corresponding main factor should be multiplied by the local weights of each sub-factor.

\section{Results}

By solving the BWM model, the weights of different factors and sub-factors were obtained. Table 2 and Fig. 2 show the weights of the main factors on the basis of responses received from the respondents in the surveys. Based on the weights obtained, it can be seen that the respondents have selected 'service processes' as the most important main factor of banking services by a big margin followed by 'interaction customer-employee' factor. The 'technological' factor is the third closely followed by 'bank environment", "communicative' factors and lastly 'interaction customer- customer'. Apart from the values of the weighting criteria, it is necessary to note the value of $\xi^{*}$ as it indicates consistency of the comparisons. The $\xi^{*}$ values are very close to zero showing a high consistency of the comparisons, and a high reliability of the results. After the weights of the main factor were obtained, the local weights for the sub-factor were calculated. After the local weights for the sub-criteria were obtained, the weights were multiplied by their corresponding main criteria weights giving an output of global weights (see Table 2.). 
Table 2

Local/Global weights of factors and sub-factors

\begin{tabular}{|c|c|c|c|c|c|c|c|}
\hline factors & $\begin{array}{l}\text { Local/global } \\
\text { weights }\end{array}$ & $\begin{array}{l}\text { Rank } \\
\text { main } \\
\text { factor }\end{array}$ & Sub-factor & $\begin{array}{l}\text { Local } \\
\text { weights }\end{array}$ & $\begin{array}{c}\text { Rank } \\
\text { sub- } \\
\text { factor in } \\
\text { main } \\
\text { factor }\end{array}$ & $\begin{array}{c}\text { Global } \\
\text { weights of } \\
\text { sub-factor }\end{array}$ & $\begin{array}{l}\text { Rank } \\
\text { sub- } \\
\text { factor }\end{array}$ \\
\hline \multirow{4}{*}{ 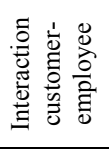 } & \multirow{4}{*}{0.252} & \multirow{4}{*}{2} & Employee's behavior & 0.286 & 3 & 0.072 & 3 \\
\hline & & & - $\quad$ Employee's responsiveness & 0.311 & 2 & 0.0783 & 2 \\
\hline & & & - $\quad$ Employee's Knowledge and skill & 0.318 & 1 & 0.0801 & 1 \\
\hline & & & Employees' appearance & 0.075 & 4 & 0.019 & 18 \\
\hline \multirow{6}{*}{ 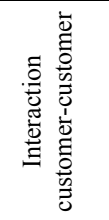 } & \multirow{6}{*}{0.058} & \multirow{6}{*}{6} & Conversation with other customers & 0.158 & 4 & 0.009 & 31 \\
\hline & & & - Word of mouth & 0.212 & 2 & 0.0123 & 28 \\
\hline & & & - Help to other customer & 0.197 & 3 & 0.0114 & 29 \\
\hline & & & Crowded & 0.23 & 1 & 0.133 & 25 \\
\hline & & & Behavior of other customer & 0.147 & 5 & 0.008 & 33 \\
\hline & & & Appearance of other customer & 0.055 & 6 & 0.0032 & 34 \\
\hline \multirow{9}{*}{ 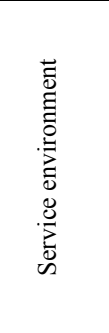 } & \multirow{9}{*}{0.15} & \multirow{9}{*}{4} & Appealingness of the interior design & 0.185 & 1 & 0.027 & 13 \\
\hline & & & Temperature and aroma & 0.087 & 7 & 0.013 & 26 \\
\hline & & & Internal Straighten & 0.176 & 2 & 0.026 & 14 \\
\hline & & & Cleanliness & 0.099 & 6 & 0.014 & 24 \\
\hline & & & Design of physical product (forms, fishes,..) & 0.104 & 4 & 0.016 & 20 \\
\hline & & & - $\quad$ Appealingness of physical product (forms, fishes, ...) & 0.086 & 8 & 0.013 & 27 \\
\hline & & & - $\quad$ Bank branch availability & 0.094 & 5 & 0.014 & 22 \\
\hline & & & - $\quad$ Bank architecture and design & 0.059 & 9 & 0.009 & 32 \\
\hline & & & - $\quad$ Available parking facilities & 0.12 & 3 & 0.018 & 19 \\
\hline \multirow{7}{*}{$\begin{array}{l}n \\
0 \\
0 \\
0 \\
0 \\
0 \\
0 \\
0 \\
0 \\
\infty\end{array}$} & \multirow{7}{*}{0.266} & \multirow{7}{*}{1} & - $\quad$ Waiting time & 0.154 & 4 & 0.041 & 10 \\
\hline & & & Working hours & 0.096 & 6 & 0.026 & 15 \\
\hline & & & Process speed & 0.191 & 2 & 0.051 & 8 \\
\hline & & & Process Standardization & 0.157 & 1 & 0.053 & 7 \\
\hline & & & Process convenience & 0.12 & 3 & 0.042 & 9 \\
\hline & & & - $\quad$ process innovation & 0.085 & 5 & 0.032 & 11 \\
\hline & & & Process customization & & 7 & 0.023 & 16 \\
\hline \multirow{3}{*}{ 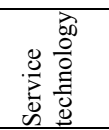 } & \multirow{3}{*}{0.183} & \multirow{3}{*}{3} & Bank technology usability & 0.363 & 1 & 0.067 & 4 \\
\hline & & & Bank technology availability & 0.299 & 3 & 0.055 & 6 \\
\hline & & & Emerging systems & 0.338 & 2 & 0.062 & 5 \\
\hline \multirow{5}{*}{. } & \multirow{5}{*}{0.09} & \multirow{5}{*}{5} & - $\quad$ Informative advertising & 0.33 & 1 & 0.03 & 12 \\
\hline & & & - $\quad$ Promotional advertising & 0.162 & 3 & 0.015 & 21 \\
\hline & & & Attractiveness Advertising & 0.15 & 4 & 0.014 & 23 \\
\hline & & & - $\quad$ Informative message & 0.243 & 2 & 0.022 & 17 \\
\hline & & & Attractiveness message & 0.155 & 5 & 0.01 & 30 \\
\hline
\end{tabular}

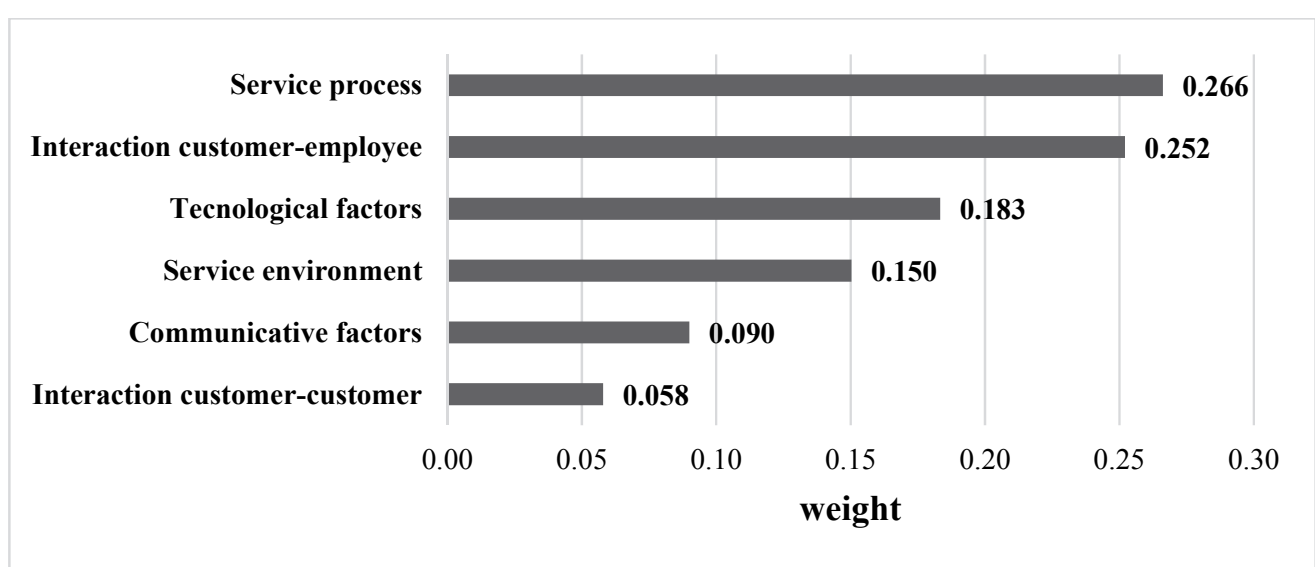

Fig 2. Main factor weights

As illustrated in Fig. 3, while the most important sub-factor of 'service process' factor is "process standardization", the sub-factor called "process customization" gains the least importance. Also in Fig. 
4 "Employee's knowledge and skills" and "employee's responsiveness" are presented as the most important sub-factors in "interaction customer-employee" factor.

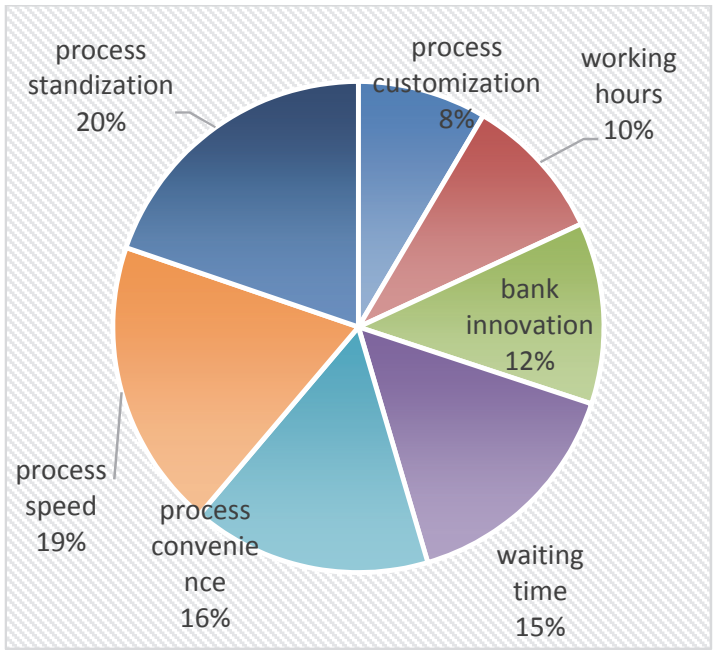

Fig 3. Weight of the sub-factor of dervice process

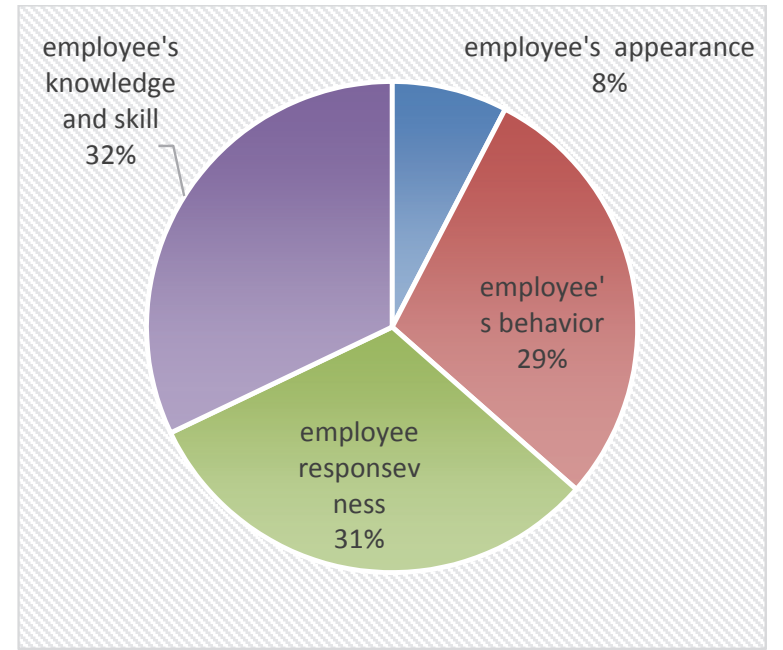

Fig 4. Weight of the sub-factor of interaction customer-employee

It can be seen from Fig 5, the weight value of "bank technology usability" and "bank technology availability" are the most and the least important sub-factors of "technological factor". As Fig 6 indicated, both "Appealingness of the interior design" and "Internal Straighten" exhibit the highest weight among all sub-factors of "bank environment" factor. However, "bank architecture" sub-factor shows the lowest weight in the above factor.

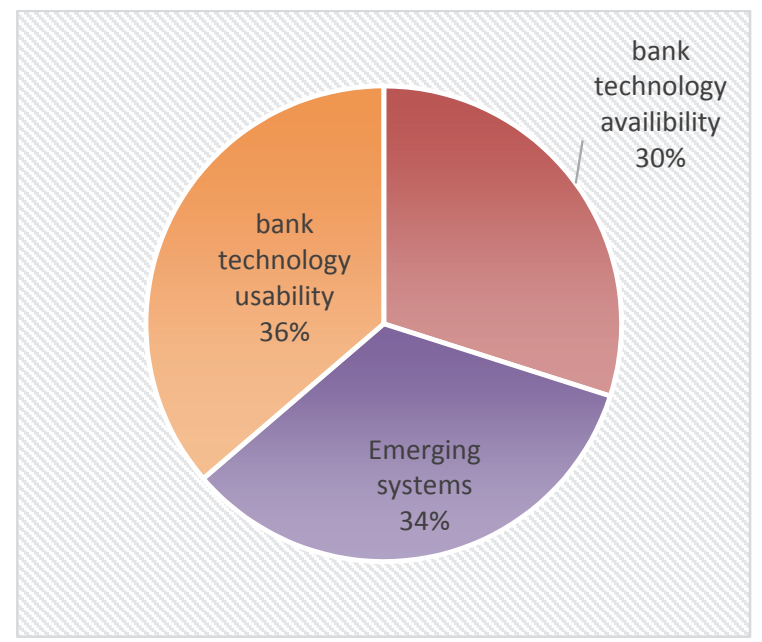

Fig. 5. Weight of the sub-factor of technology

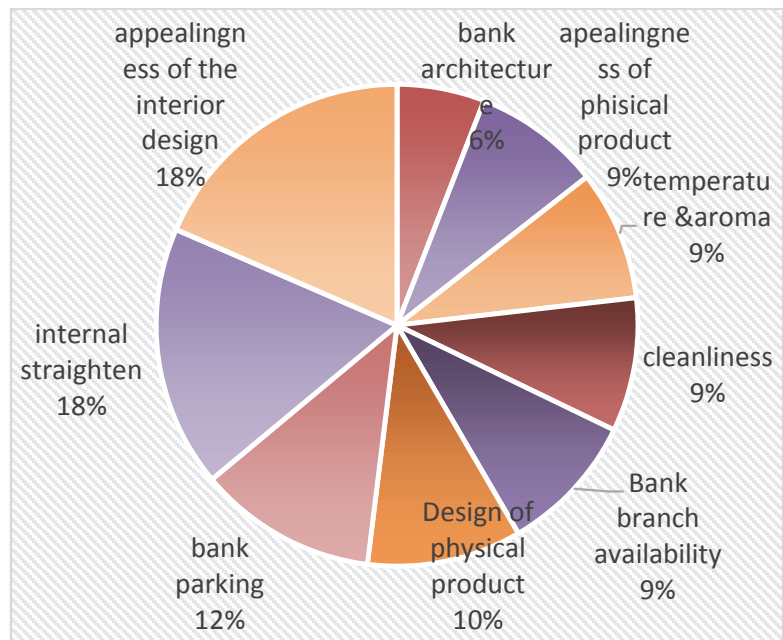

Fig. 6. Weight of the sub-factor of bank environment

Fig 7 shows that "Informative advertising "is the most important and "Attractiveness message "is the least important sub- factors of "communicative factor". As it is illustrated in Fig. 8, "crowded" and "appearance of other customer" show the highest and the lowest weights among the sub-factors of "Interaction customer-customer " respectively. 


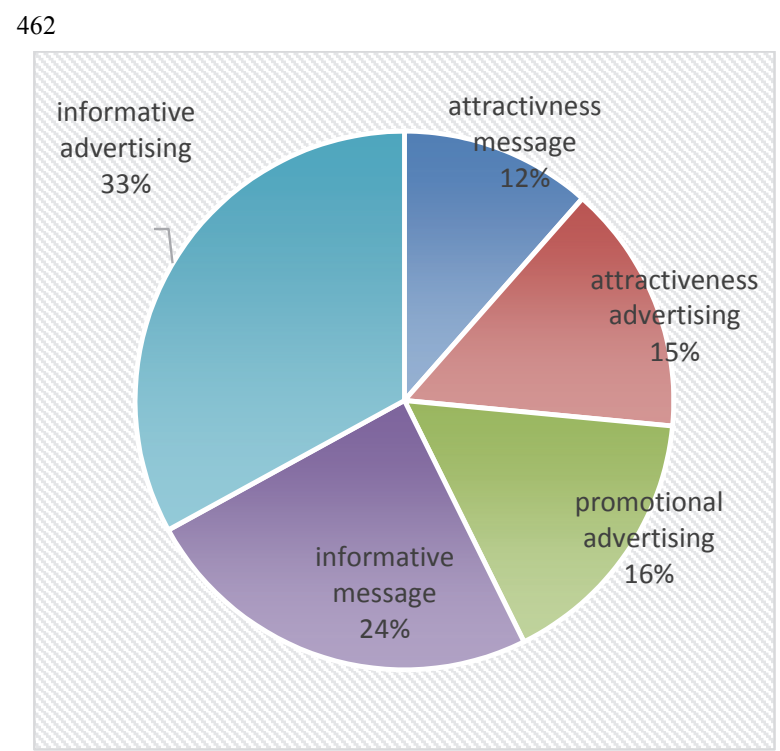

Fig. 7. weight of sub-factor of communicative factor

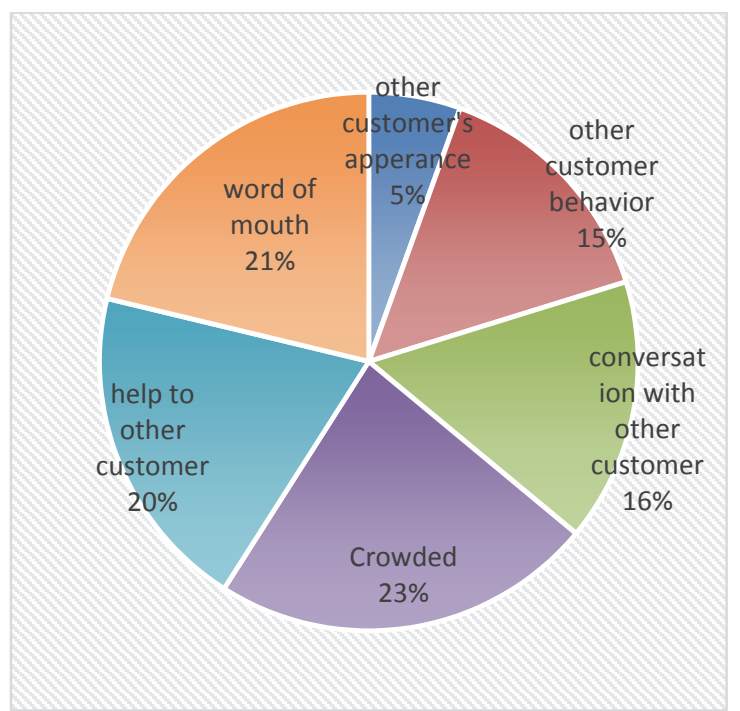

Fig. 7. Weight of sub-factor of communicative factor

As can be seen from Table 2, the global weight values of sub-factor of 'interaction customer-employee' are the highest. 'Knowledge and skill' is seen as the most important sub-factor by the respondents followed by 'responsiveness'. The sub-factor of 'employee's behavior' comes next. On closer attention to sub-factor of 'technological factor' and 'process' it can be seen that sub-factor of 'Bank technology usability' had higher values than those of 'technological factor' sub-factor.

\section{Discussion}

In general, service providers are willing to increase the customer satisfaction and customer loyalty. In this case, creating a favorable and memorable service experience is one of the valuable strategies. Thus, identifying the factors of the service experience plays a significant role for the success of organizations. Thus, the present study aimed at identifying and prioritizing the factors forming the service experience in banks by using the BMW method. For this purpose, firstly, the literature and interview with bank customers were used to collect the required data. The analyzed data revealed overall six factors and 34 sub-factors forming the service experience including the interaction customer-employees, service process, interaction customer-customer, bank environment, technological and communicative factors each one composed of some sub-factors. Then, the significance and the preference of the component and sub-factor from customer's viewpoint were determined by the BMW method.

The results of this study indicated that while the service process, interaction customer-employees and technological factors were the most important factors, bank environment and communicative factor and interaction customer-customer were the least important factors in forming the service experience from bank customers' viewpoints. The results obtained from the global weights showed that the knowledge and skill of employees were the most important factors in forming the favorable service experience. Although there are not a large number of studies on evaluating the factors of service experience, the similar findings of previous studies shed light on the findings of this study. Garg et al (2012), for instance indicated that convenience, employees, and servicescape had the highest importance compared to other success factors of service experience. Thus, firstly the customer convenience at each touch point such as available parking facilities, bank location, hygienic environment, and speed should be provided which can be a significant motivator for creating memorable experience. Secondly, the behavior and responsiveness of employees considerably create service experience. Therefore, it is necessary to train the appropriate human skills to the employees for increasing customer satisfaction. Thirdly, bank service experience is highly affected by servicescape elements such as hygiene facilities, comfortable seats, cleanliness, accessibility, aesthetics, displays, layout, equipment (Wakefield \& 
Blodgett, 1996). By equipping the physical environment appropriately, the banks can enrich their service experience. In addition, Chahal and Duta (2015) considered the employee knowledge and competencies as the most important factors in creating the bank service experience.

Furthermore, as the results obtained from the global weights of each sub-factor are close to each other indicating that all factors are very significant in enriching the service experience, the bank managers should properly pay attention to all these sub-factors. However, the managers should not neglect the factors with less weight because a part of effectiveness of these factors is beyond the control of the bank. Customer satisfaction is a set of positive and negative service experiences (Meyer \& Schwager, 2007). Thus, the managers cannot ignore the factors with less priority because they may have an effective role in customer satisfaction.

One of the positive points of this study is that the identified factors were general for measuring the service experience from banking services. Since service experience has a subjective and individual nature, it needs to be studied from the customers' viewpoints. BMW method quantifies the customer judgments and numerical results which can be effectively used by managers.

\section{Conclusions}

This study helped the managers identify the factors of the service experience from banking services. Furthermore, it helped the managers improve the quality of their services based on customer expectations and preferences, so that this study showed the most important factors for creating the favorable and memorable experiences of banking services. Managers cannot often cope with all factors at the same time due to the limitation of sufficient resources. Thus, they can understand the significant factors by prioritizing the most important ones to allocate their resources for enriching the service experience and increase the customer satisfaction. Due to the high significance of service process and interaction customer-employees in creating the favorable and memorable service experience, it is suggested to consider the convenient and standard processes in designing the banking service and decreasing the waiting time of customers in banks by increasing the speed in banking affairs. In addition, it is suggested to select individuals with high and appropriate responsiveness to customers' requests and with adequate knowledge and skill in doing the banking affairs. Thus, the employees should be continuously trained to increasingly get familiar with the processes of banking affairs in order to provide customers with better services. It is recommended that further studies use the structural equation modeling to confirm model of this study. In addition, since this study was examined in the utilitarian services setting, other researchers may identify and prioritize the factors of the service experience in hedonic services. As, identifying the factors of service experience is considered as a part of new service design process; it is suggested to use the proposed model of this study to design the service experience and new services in different sectors.

\section{References}

Abadi, F., Ghasemian, I., Arab, A., \& Alavi, A. (2018). Application of Best-Worst method in evaluation of medical tourism development strategy. Decision Science Letters, 7(1), 77-86.

Askarifar, K., Motaffef, Z., \& Aazaami, S. (2018). An investment development framework in Iran 's seashores using TOPSIS and Best-Worst multi-criteria decision making methods. Decision Science Letters, 7(1), 55-64.

Bateson, J. E. G. (1995). Managing services marketing: text and readings (4th ed.). South-Western College Pub.

Chahal, H., \& Dutta, K. (2015). Measurement and impact of customer experience in banking sector. Decision, 42(1), 57-70.

Garg, R., Rahman, Z., Qureshi, M. N., \& Kumar, I. (2012). Identifying and ranking critical success factors of customer experience in banks. Journal of Modelling in Management, 7(2), 201-220 
Garg, R., Rahman, Z., \& Qureshi, M. N. (2014). Measuring customer experience in banks: scale development and validation. Journal of Modelling in Management, 9(1), 87-117.

Gentile, C., Spiller, N., \& Noci, G. (2007). How to sustain the customer experience: An overview of experience components that co-create value with the customer. European Management Journal, 25(5), 395-410.

Ghaffari, S., Arab, A., Nafari, J., \& Manteghi, M. (2017). Investigation and evaluation of key success factors in technological innovation development based on BWM. Decision Science Letters, 6(3), 295-306.

Grace, D., \& O'Cass, A. (2004). Examining service experiences and post-consumption evaluations. Journal of Services Marketing, 18(6), 450-461.

Holbrook, M. B., \& Hirschman, E. C. (1982). The experiential aspects of consumption: Consumer fantasies, feelings, and fun. Journal of Consumer Research, 9(2), 132-140.

Lemke, F., Clark, M., \& Wilson, H. (2011). Customer experience quality: an exploration in business and consumer contexts using repertory grid technique. Journal of the Academy of Marketing Science, 39(6), 846-869.

Licata, J. W., \& Chakraborty, G. (2009). The effects of stake, satisfaction, and switching on true loyalty: a financial services study. International Journal of Bank Marketing, 27(4), 252-269.

Meyer, C., \& Schwager, A. (2007). Understanding customer exprience. Harvard Business Review, $85(2), 116-126$.

Pine, J., \& Gilmore, J. H. (1998). Welcom to the experience economy. Harvard Business Review, 76(4), 97-105.

Rahman, Z. (2006). Customer experience management-A case study of an Indian bank. Journal of Database Marketing \& Customer Strategy Management, 13(3), 203-221.

Rajaobelina, L., \& Bergeron, J. (2009). Antecedents and consequences of buyer-seller relationship quality in the financial services industry. International Journal of Bank Marketing, 27(5), 359-380.

Rezaei, J. (2015). Best-Worst multi-criteria decision-making method: Some properties and a linear model. Omega, 64,120-134.

Rezaei, J. (2016). Best-Worst multi-criteria decision-making method. Omega, 53, 49-57.

Rezaei, J., Kothadiya, O., Tavasszy, L., \& Kroesen, M. (2018). Quality assessment of airline baggage handling systems using SERVQUAL and BWM. Tourism Management, 66, 85-93.

Rosen, E., \& Waller, K. (2009). Consumer brand touch points: a case study of Hennes \& Mauritz in Sweden \& Germany. University of Gothenburg.

Shaw, C., \& Ivens, J. (2003). Building great customer experiences. Palgrave Macmillan (Vol. 5).

Verhoef, P. C., Lemon, K. N., Parasuraman, a., Roggeveen, A., Tsiros, M., \& Schlesinger, L. a. (2009). Customer experience creation: determinants, dynamics and management strategies. Journal of Retailing, 85(1), 31-41.

Wakefield, K. L., \& Blodgett, J. G. (1996). The effect of the servicescape on customers' behavioral intentions in leisure service settings. Journal of Services Marketing, 10(6), 45-61.

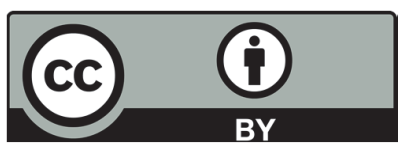

(C) 2018 by the authors; licensee Growing Science, Canada. This is an open access article distributed under the terms and conditions of the Creative Commons Attribution (CC-BY) license (http://creativecommons.org/licenses/by/4.0/). 